\title{
System of energy criteria in the justification of technical units for field production
}

\author{
Viktor B. Rykov ${ }^{1}$, Sergey I. Kambulov ${ }^{1, *}$, Evgeny I. Trubilin² ${ }^{2}$ and Yuri K. Kastidi ${ }^{2}$ \\ ${ }^{1}$ Federal State Budget Scientific Institution «Agricultural Scientific Center" Donskoy unit» «North \\ Caucasian Research Institute of Mechanization and Electrification of Agriculture», Zernograd, \\ Russia \\ ${ }^{2}$ Federal State Budgetary Educational Institution of Higher Education «Kuban State Agrarian \\ University named after I.T. Trubilin» Krasnodar, Russia
}

\begin{abstract}
The article shows the importance and necessity of energy analysis of both machine technology, as a whole, and machinetechnological aggregates in order to compare several variants of technical solutions of the designed equipment (power units, machines, aggregates) for field cultivation. The necessity of introducing additional energy criteria when designing machine technologies and creating technical means for their implementation is justified.
\end{abstract}

The real situation with energy resources in Russia requires a change in approaches to the design of machine technologies and the creation of technical units for their implementation in the field production.

Agricultural production is one of the main consumers of energy resources, in particular, petroleum products. The agro-industrial complex consumes up to $15 \%$ of all energy resources and up to $40 \%$ of petroleum products (gasoline, diesel fuel, oils).

Currently used methods of evaluating technical units used to produce agricultural products based on labor costs and economic indicators (in particular, the specified costs) are in some cases insufficient, since these indicators have significant fluctuations determined by the pricing system, and do not allow you to determine the level of necessary energy costs of production. The existing and increasing energy deficit in the world requires a different approach in assessing both individual technical units, complexes of machines, technological processes, and mechanized technologies as a whole.

Energy analysis allows you to evaluate new and existing technologies, while energy analysis indicators do not replace, and this is an important point, but complement the assessment of technologies by other indicators, such as labor costs, economic efficiency indicators, etc.

The following points should be taken into account.

The most complete use of the traction and dynamic capabilities of power units

is realized in equipment with a rationally selected width and working speeds of movement [1].

\footnotetext{
${ }^{*}$ Corresponding author: kambulov.s@mail.ru
} 
This allows you to reduce the metal consumption of a set of technical units, save fuel and lubricants, optimize wages and depreciation charges. At the same time, the highest performance is achieved. However, this conclusion is valid only for certain technological operations outside of their connection with the performance of others. If you take the machine technology completely, the performance of the operations performed must be consistent with the main one, and their effectiveness will depend on it. For example, when sowing the main operation is directly sowing, and auxiliary-pre-sowing cultivation, loading seeds and fertilizers into vehicles, transporting seeds and fertilizers, loading into seeders, post-sowing rolling, during the grass harvesting process, the main operation is mowing, auxiliary - selection, pressing, transportation, storage.

For the coordinated operation of the set of necessary technical units, it is necessary to change the operating mode of individual units in order to equalize the daily performance of all technological units.

The potential of effective use of machine-technological units (MTU) is most evident in the technological complex (system) of machines [2, 3].

A distinctive feature of a rational complex (system) of machines is the completion of a complete cycle of works in field cultivation and harvesting of crops. Such conditions are created in all types of agricultural enterprises that differ from each other in different production volumes. In the general statement of the problem of justification of technical units, the energy criteria form a discrete number of capacities of energy units for performing each operation throughout the entire operation cycle. The type of commodity producers that form the daily volume of work is a limitation in determining the power of the energy units used. From a discrete series, it is necessary to choose such a power (and justify the energy units for it) or a combination of two or more capacities that will ensure the necessary efficiency of the machine technology as a whole.

The final stage of evaluating the effectiveness of each single capacity will be their superimposition on a set of representative objects that characterize the average values of the functioning of technical units in various types of producers.

The problem statement can be changed if it is necessary to evaluate and compare several variants of technical solutions of the projected equipment (power units, machines, aggregates) for field cultivation.

What criteria can and should be used in the energy analysis of both the technology as a whole and the machine-technological units separately?

The energy efficiency coefficient of technology is the ratio of energy contained in obtained agricultural products to the total fuel and energy costs for its production which is taken as the main criterion for the energy assessment of machine technologies for cultivating and harvesting crops in the field. Energy consumption and output in products should be expressed in comparable units ( $\mathrm{MJ} / \mathrm{kg}$ or $\mathrm{Kcal} / \mathrm{kg})$. Total fuel and energy costs include both direct and indirect costs, i.e. costs embodied in the volumes and materials used in the process or technology. For example, the estimated energy costs for the production of mechanization units, mineral fertilizers, pesticides, etc. the energy contained in the final product can be recalculated by knowing the yield (C/ha or $t / h a)$ or gross harvest and the energy equivalent of the main product $(\mathrm{MJ} / \mathrm{hw}$ or $\mathrm{MJ} / \mathrm{t})[4,5]$.

Direct energy costs can be calculated by knowing the fuel consumption per unit of processed area, unit of production, electricity consumption, coefficient of fuel heat content in $\mathrm{MJ} / \mathrm{kg}$, coefficient of conversion of $\mathrm{kW} / \mathrm{h}$ to $\mathrm{MJ}$ and Kcal to $\mathrm{MJ}$ [6].

The embodied energy costs, as already mentioned, include energy costs for the production of mineral fertilizers and herbicides. The transfer of energy costs to the final product is determined from the application rate and the duration of the substance.

The total cost of energy includes complex components as well as the energy consumption of living labor and the energy intensity of mechanization. 
Live labor costs are the energy costs of maintenance personnel based on established norms that provide for gradation of labor into very heavy, heavy, medium, light and very light. Means of mechanization transfer the energy to the product. This includes energy equivalent machines (subject to complexity), and weight, cost of maintenance, overhaul and current repairs, performance cars, etc. When assessing the energy intensity of post-harvest technological operations, the main criterion for the efficiency of post-harvest technological processes is the energy costs per unit of a processed product. In addition to direct energy costs, the components of costs are energy costs for the production of chemical additives, preservatives, etc. (if such are used), the cost of human labor, the energy intensity of equipment and production facilities (sites, storage, etc.). Thus, using the above approach, it is possible to conduct a comparative assessment of technologies for the production of agricultural products in the field of energy consumption. In the energy assessment, especially comparative, for individual technical means used in the implementation of technologies for the production and processing of agricultural products, the most accepted criteria can be used:

- energy efficiency coefficient of MTU - the ratio of target energy costs to direct energy costs in the process under consideration;

- energy intensity of mechanization equipment - total fuel and energy costs for production, repair and maintenance of mechanization units;

- MTU enerqy efficiency coefficient is the ratio of the total fuel and energy costs of the technological process performed by the new and basic units.

Considering all the proposed examples of energy costs, it should be noted that the share of direct energy costs in the total balance of energy costs is the largest. Therefore, when developing, creating or selecting units of mechanization for field cultivation, first of all, the advantage should be given to machines and aggregates with less specific fuel consumption, less traction resistance, and less specific metal content.

Saving of fuel and energy resources in the field cultivation is achieved by: careful and timely adjustment of the fuel-feeding equipment of the energy units used; reducing the weight parameters of machines by a meter of the width of the capture; combining technological operations; using unified load-bearing systems; replacing energy-intensive technological operations with less energy-intensive ones; rational acquisition of machinetechnological units.

The amount of fuel consumed in the field cultivation, for example, is significantly affected by the structure of the machine and tractor park. The lack of the necessary set of machines to energy-saturated energy units leads to underutilization of engine power on low-energy operations due to restrictions, for example, speed (on seeding), and as a result, fuel overspending by 8-10\% [7]. Rational aggregation of MTU, in particular, tillage units, allows to reduce fuel consumption significantly, especially in general operations, such as basic tillage, care of fields under fallow, seeding, crop care. Correct energy assessment allows, first, to determine the most preferred compositions of machine and tractor units (MTU) for certain technological operations, and secondly, to prevent the introduction of technical units into production with indicators of fuel and energy costs that exceed the available minimum level [7, 8].

As an illustration, let's give an example of tillage units. Thus, estimating the total energy costs per hectare of cultivated area the technological operations for peeling and disking stubble, preference should be given to MTU with disc huskers. The reduction in total energy costs even with a double pass of $4 \# 4$ Class 3 and the ADG-15 disk husker, compared to the unit from the same energy medium and a disk harrow of the BDT-7 type, is $37.7 \%$.

Other example. Soil preparation for winter crops for non-fallow precursors both from agrotechnical and energy points of view, it is advisable to conduct only combined tillage 
units such as KUM, AKM. At the same time, the total energy cost per unit of the cultivated area is almost half the energy cost when preparing the soil for winter crops using traditional technology of separate aggregates (peeling, plowing, cultivation) [9].

In the summer, processing of fallow fields to a depth of 4-6 cm (as required by agrotechnical requirements) is advisable to use units such as VKSH-15 or KVS-11 with moisture-saving working bodies such as "shark fin". Not to mention the agrotechnical advantages of such working bodies (stable operation at a depth of 4-6 cm, 100\% cutting of weeds, excluding the removal of wet layers to the daytime surface), reduction in energy intensity in comparison with the most low-energy cultivator is up to $30.6 \%[2,3]$.

Analysis of currently used arable units in energy costs per unit of cultivated area shows that the most economical is the unit consisting of the power unit of the traction class 5 of wheel formula $4 \# 4$ and chainless cultivator with a width of $18 \mathrm{~m}$. Almost the same energy has the unit consisting of the power unit of a traction class of 3 wheel formula $4 \# 4$ and chainless cultivator with a width of $12 \mathrm{~m}$. The reduction of energy costs per unit of processed area for a chainless unit based on a power unit class 3 compared to three cultivator units based on hitches and cultivators with a width of $4 \mathrm{~m}$ at a processing depth of $10-12 \mathrm{~cm}$ is $17 \%, 8-10 \mathrm{~cm}-17.6 \%, 6-8 \mathrm{~cm}-13 \%$.

Evaluating the seeding units from the point of view of energy saving, it is clear that the preferred units are based on universal grain seeders with a width of $12 \mathrm{~m}$ with power units of traction class 3 and $18 \mathrm{~m}$ - for power units of traction class 5 . At the same time, along with a lower metal consumption of aggregates, energy consumption per unit of sown area is also reduced by $27.1 \%$ compared to coupling aggregates of the same width [10].

Decrease of specific energy costs the rotary hoe of the MRSH type has a decrease in specific energy consumption compared to the harrowing unit based on the SG-21 hitch - by 42.6\% when harrowing crops (pre-emergence and post-emergence processing).

These examples and many such examples show quite convincingly that the consideration of energy criteria in the justification, design, implementation and use of mechanized units in the field cultivation should be mandatory along with other accepted criteria of an economic and agrotechnical nature.

\section{References}

1. Pakhomov, V.I. Justification of optimal selection of mounted and trailed machines and equipment for aggregating them with self-propelled agricultural machines when performing a complex of agricultural works / V.I. Pakhomov, V.B.Rykov, S.I. Kambulov, I.A. Kambulov, M.V.Danilov, L.I. Vysochkina, E.V.Gerasimov, G.G.Shmatko // Zernograd: FSBEI SKNIIMEA, 2016. - 74 p.

2. Rykov, V.B. Features of winter wheat cultivation in the conditions of insufficient moisture in Rostov region / V.B. Rykov, S.I. Kambulov, I.A.Kambulov, V.I. Vyalkov, V.I. Taranin, N.V.Shevchenko, N.G. Yankovsky // Zernograd: FSBEI SKNIIMEA, 2010. - 172 p.

3. Pakhomov, V.I. Experience of winter wheat cultivation in the conditions of insufficient moisture / V.I.Pakhomov, V.B.Rykov, S.I.Kambulov, N.V.Shevchenko, E.L.Revyakin // M.: «Rosinformagrotech», 2015. - 160 p.

4. Methods of energy analysis of technological processes in agricultural production. - M.: VIM, 1995. - 95 p.

5. Methods and methodology of energy assessment of agricultural technologies in agricultural landscapes [Electronic resource]. Mode of access: http:/yadyra.ru/attachments/Metodika - energeticheskoiotsenki. - pdf. - M., 2007.

6. Kambulov, S.I. Development of units for energy assessment of crop production technologies / S.I.Kambulov, N.V.Shevchenko, V.B.Rykov, E.B.Demina, 
V.V.Kolesnik, S.D. Ridny // In the collection of works: State and prospects of development of agricultural mechanical engineering: Collection of works - Rostov-onDon «Interagromash-2017». - 2017. - P. 87-90.

7. Pakhomov, V.I. Results of comparative assessment of mechanized technologies of grain crop production / V.I. Pakhomov, V.B. Rykov, S.I. Kambulov // Grain production of Russia. - 2016. -№ 1. - P. 58-62.

8. Rykov, V.B. Development of effective mobile technological units for the conditions of the South of Russia / V.B.Rykov, S.I. Kambulov, E.I.Trubilin, N.V.Shevchenko / Krasnodar, 2019. - 265 p.

9. Burbel, A.F. Agrotechnology of fields of the South of Russia / A.F. Burbel, A.N. Belan, B.A. Zemlyansky, A.S. Naydenov. - Eysk, 1996. - 181 p.

10. Rykov V.B. Organizational and technological project of the production of strong and solid (valuable) wheat in the conditions of insufficient moisture with the use of complexes of machines with adaptive working bodies / V.B. Rykov, N.V.Shevchenko, V.I.Vyalkov, V.I. Taranin // Zernograd: FSBEI SKNIIMEA. - 2008 . - 140 p. 